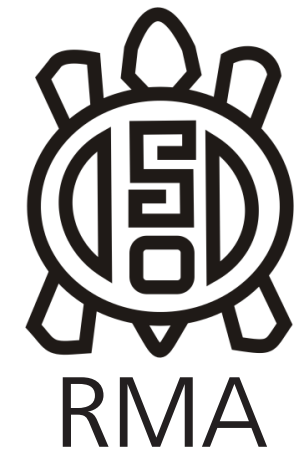

Dossier

\title{
Las relaciones humanos/animales en las sociedades prehispánicas del Paraná Medio e Inferior: un giro ontológico
}

\author{
Human/animals relations in the pre-Hispanic societies from the Middle \\ and Lower Paraná River: an ontological turn
}

María Laura Bastourre*

*División Arqueología, Facultad de Ciencias Naturales y Museo, Universidad Nacional de La Plata, Argentina. E-mail: laurabastourre@yahoo.com.ar

\begin{abstract}
Resumen
Se retoman los aportes de la antropología amazónica a las arqueologías preocupadas en los problemas ontológicos. El objetivo es abordar, a la luz de estas ideas, las relaciones humanos/animales en las sociedades prehispánicas del Paraná Medio e Inferior. La información disponible sobre los modelados zoomorfos de la entidad arqueológica Goya-Malabrigo sugiere que los filtros ontológicos que operaron en el pasado fueron cercanos a un régimen animista o perspectivista. Sin embargo, se propone que un giro ontológico más crítico debería superar las interpretaciones representacionalistas de estas entidades (i.e. que "visión de mundo" expresan) para centrarse en sus capacidades de afección. Esto llevó a poner el foco en los conceptos de transformación y especificación de los cuerpos y a explorar otras aristas y materiales involucrados en las relaciones humanos/animales en estas sociedades. Se propone que tanto los aspectos considerados tradicionalmente como "materiales" (por ej. subsistencia) como los que suelen asociarse al "mundo simbólico" (por ej. representación de animales) constituyen todos ellos entramados de acciones y relaciones que involucran múltiples agencias, no solo humanas. Es a partir de este tejido relacional que emergen objetos y sujetos, materiales y significados, animales y humanos, sin que puedan establecerse a priori distinciones ontológicas entre ellos.
\end{abstract}

Palabras clave: Perspectivismo; Naturaleza/cultura; Goya-Malabrigo; Zooarqueología; Apéndices zoomorfos.

\begin{abstract}
The contribution of Amazonian anthropology to archaeologies of ontology is assessed in order to explore human/ animals relations in the pre-Hispanic societies from the Middle and Lower Paraná River. Available archaeological information regarding Goya-Malabrigo pottery with zoomorphic appendages suggests that past ontological filters can be linked to animic or perspectivistic regimes. A more critical ontological turn, however, should go beyond representationalism and, instead of wondering what "worldviews" these zoomorphic figures express, it could benefit from focusing on its affective and agentive capacities. To this regard, the concepts of body transformation and "specification" are addressed, which led to considering other aspects and materials involved in human engagements with animals in the past. It is argued that practices commonly labeled as "material" (eg. subsistence) as well as those traditionally linked to "symbolic worlds" (e.g. animal representations) are both better understood as materially interwoven actions and relations involving multiple agencies, not just human ones. It is from this relational process that subjects, objects, materials, meanings, humans and animals emerge, without a priori ontological distinctions between them.
\end{abstract}

Keywords: Perspectivism; Nature-culture; Goya-Malabrigo; Zooarchaeology; Zoomorphic appendages.

\section{Introducción}

En este trabajo me propongo explorar las potencialidades del reciente "giro ontológico" en arqueología (sensu Alberti, 2016) para generar nuevas comprensiones en torno a las interrelaciones entre humanos y animales, tomando como caso de estudio las sociedades que habitaron los ambientes ribereños del Paraná Medio e Inferior durante el Holoceno tardío. Buena parte del registro arqueológico de esta región, correspondiente al lapso temporal entre ca. 2000 y 300 años AP, ha sido englobado bajo lo que se conoce como entidad arqueológica Goya-Malabrigo (sensu Politis y Bonomo, 2012), cuyas características más sobresalientes incluyen: la construcción de "cerritos" utilizados con fines habitacionales y funerarios, una alfarería distintiva con modelados zoomorfos de loros y otros animales, y una subsistencia basada en la pesca, la caza de mamíferos acuáticos, la recolección y la 
horticultura a pequeña escala (ver síntesis en Politis y Bonomo, 2018). Retomaremos también datos de sitios arqueológicos del Delta Inferior del Paraná, que no han sido asignados a esta entidad arqueológica, aunque comparten con ella ciertas características generales, como la ocupación de geoformas elevadas (de origen natural y antrópico) dentro de ambientes inundables y las prácticas de subsistencia fuertemente orientadas a los ambientes acuáticos (Acosta, 2005; Politis et al., 2017). Asimismo, se utilizará información histórica referida a los grupos genéricamente conocidos como "chaná-timbú", cuya revisión brinda elementos de comparación interesantes para explorar los contextos materiales abordados en este trabajo. Dicha aproximación se fundamenta en la continuidad histórica que existiría entre estos grupos, descritos en las fuentes documentales de los siglos XVI y $\mathrm{XVII}$ y las manifestaciones arqueológicas que conocemos como Goya-Malabrigo (Ceruti, 2003; Politis y Bonomo, 2012, 2018; Serrano, 1950).

Sucintamente, podríamos decir que, a lo largo de la historia de las investigaciones en el área de estudio, los modos en que se ha abordado el tema de las relaciones entre humanos y animales en estas sociedades han girado en torno a dos ejes fundamentales, aunque no necesariamente excluyentes. Por un lado, los enfoques culturalistas, de larga tradición en la región, vieron a los animales como una fuente de "inspiración estética" para los ceramistas ribereños y consideraron las representaciones zoomorfas como un elemento diacrítico para la delimitación de las unidades culturales del área (por ej. Caggiano, 1984; Serrano, 1950). Los rasgos arqueológicos distintivos de estas culturas eran entendidos como correlatos materiales de un conjunto de normas ideales compartidas por sus "portadores"; así, las ideas y representaciones en torno a los animales, plasmadas materialmente en la cerámica, caracterizarían a la cultura de Goya-Malabrigo. Trabajos más recientes, inspirados en la arqueología interpretativa, también han estudiado los modelados zoomorfos desde una perspectiva representacionalista, y han enfatizado el rol de los animales como recursos metafóricos y simbólicos (Ottalagano, 2008, 2010). Por otro lado, las vertientes "ecológicas" (ya sea en sus variantes adaptacionistas, procesualistas o ecológico-evolutivas) han puesto el foco en la importancia de los animales como recursos económicos y han abordado el comportamiento cultural desde una lógica adaptativa, o bien, utilizando modelos de optimización (por ej. Acosta, 2005; Ceruti, 2003).

Estos dos conjuntos de enfoques privilegian uno $u$ otro polo del par naturaleza/cultura: en los primeros la naturaleza es un sustrato pasivo para la elaboración cultural, mientras que en el segundo es el ambiente y sus recursos el que define el carácter de los patrones culturales, que quedan así subsumidos a leyes naturales universales estudiadas por las ciencias positivas. Sin embargo, de esta manera, ambos reproducen la división de tareas diseñada por el pensamiento moderno. Este imagina que la naturaleza, con sus leyes universales y sin equívocos, abordadas por las ciencias naturales, sería el asiento sobre el cual se desarrolla la cultura, con sus variadas manifestaciones contingentes, estudiadas por las humanidades (Descola, 2011). Así, distintos discursos arqueológicos, ya sea que se inscriban en tradiciones positivistas-naturalistas o, alternativamente, humanistasconstructivistas, se encuentran atravesados por el mismo dualismo ontológico, aquel entre naturaleza y cultura, que sustenta también las divisiones básicas entre lo material y lo ideal, el objeto y el sujeto o el cuerpo y la mente (Haber, 2004; Thomas, 2002).

\section{Naturaleza/cultura y el giro ontológico}

La antropología amazónica ha contribuido enormemente al desarrollo teórico sobre las relaciones animales/ humanos (y en un sentido más amplio, naturaleza/ cultura), trabajando conceptos como animismo (Descola, 2014), eco-cosmología (Århem, 1996), perspectivismo (Viveiros de Castro, 2004a, 2010) y familiarización (Erikson, 2000; Fausto, 2007). Este acápite no tiene como objetivo revisar esta extensa y nutrida tradición de investigaciones, sino que se centrará en las críticas al esquema binario naturaleza/cultura expuestas por Philippe Descola (2014) y, especialmente, Eduardo Viveiros de Castro (2004a, 2004b), y en el diálogo entre estas últimas ideas y las arqueologías de la ontología (Alberti, 2016).

Tal como la etnografía de las tierras bajas sudamericanas ha mostrado, el dualismo naturaleza/cultura no logra captar adecuadamente las concepciones que numerosos pueblos no modernos poseen sobre los animales, las plantas y otros seres de su entorno, a los que atribuyen cualidades que muchos estarían dispuestos a asociar exclusivamente a los humanos (Århem, 1996; Descola, 2011; Politis y Saunders, 2002; Viveiros de Castro, 2004a). Tradicionalmente, la antropología ha entendido este tipo de fenómenos como el resultado de las diferentes "visiones de mundo", cultural e históricamente situadas, que existen sobre la naturaleza. El problema de este enfoque es que refuerza el dualismo original, ya que remite a las diversas concepciones y creencias (culturales) que existen sobre el mundo (natural), un mundo que, justamente, se define bajo los parámetros universalizantes del pensamiento occidental. Así, las ontologías de otros se reducen a epistemologías exóticas y, en última instancia, equivocadas (Alberti y Marshall, 2009; Viveiros de Castro, 2003). Descola (2014) argumentó que, en lugar de un mundo y diversas versiones culturales sobre él, existen distintos estilos de hacer mundos. Los animales y otras entidades no son ni objetos con cualidades esenciales, que pueden ser captadas por la mente humana (como buscaría la ciencia positiva), ni meras construcciones sociales que dan sentido a una materia prima (como argumentaría el constructivismo). Son más bien, grupos de cualidades y relaciones que los humanos pueden 
actualizar o no, detectar o ignorar, según los "filtros ontológicos" aplicados. La variedad de formas de hacer mundos no resulta entonces de cosmovisiones, patrones culturales o nociones similares, sino de distintos regímenes ontológicos: estilos de pensamiento y acción que echan mano a diferentes supuestos sobre los tipos de seres del mundo y sobre cómo estos se relacionan entre sí. Estos estilos fueron caracterizados como esquemas de práctica o dispositivos de encuadre, que serían en parte innatos -resultado de ciertas características universales del proceso cognitivo- pero también el resultado de los modos concretos en que se coordinan las agencias humanas y no humanas en un entorno dado. Son estructuras que organizan percepciones, habilidades y acciones, y que permiten gestionar el proceso de "interagencia" (Descola, 2014).

Una de las funciones fundamentales de los dispositivos de encuadre es establecer identidades entre los elementos del mundo, agrupándolos o disociándolos según sus similitudes y diferencias. Un supuesto clave de la propuesta de Descola $(2011,2014)$ es que la conciencia de una dualidad entre lo que llama "interioridad" y "fisicalidad" es una característica universal de la cognición humana. La primera refiere a los atributos asociados ordinariamente al "alma", el "espíritu" o la "conciencia" (como intencionalidad, subjetividad, reflexividad, afectos y capacidad de significar), mientras que la fisicalidad concierne a la forma y los procesos fisiológicos, perceptivos, sensoriales y motores. Según los filtros ontológicos que se apliquen, los seres humanos pueden enfatizar o minimizar la continuidad y la diferencia entre sí mismos y los otros, ya sea a partir de la naturaleza de la interioridad y/o de la fisicalidad. Este sistema de contrastes resulta, según el autor, en un esquema cuatripartito de ontologías: el totemismo, que resalta las similitudes entre personas humanas y no humanas, concernientes tanto a la fisicalidad como a la interioridad; el analoguismo, que destaca, inversamente, las discontinuidades (graduales) en ambos planos; el naturalismo (similar fisicalidad y diferente interioridad) y el animismo (misma interioridad y distinta fisicalidad). Estos modos de identificación no constituyen tipos aislados y excluyentes; en situaciones reales lo más común es la hibridación, aunque un modo pueda dominar ligeramente sobre otro (Descola, 2011, 2014). A los fines de este trabajo, interesa explorar especialmente el contraste entre naturalismo y animismo.

El naturalismo, ontología dominante en las sociedades occidentales, concibe que todos los seres del mundo se encuentran abarcados por una misma naturaleza unificadora: las leyes de la física atañen a todas las cosas materiales y, como humanos, compartimos con otros organismos los mismos procesos biológicos y fisiológicos básicos, en virtud de una historia evolutiva común. Lo que distingue a los humanos es la conciencia, el alma, la subjetividad, el lenguaje y la cultura, criterio este último a partir del cual se definen también las propiedades y las fronteras entre distintas agrupaciones humanas. El animismo invierte los contrastes, ya que plantea que humanos y no humanos poseen el mismo tipo de interioridad, pero se diferencian por la naturaleza de sus cuerpos. En los sistemas animistas -muy comunes en las tierras bajas sudamericanas, América del Norte y parte de Asia- los animales (y otras entidades) están dotados de subjetividad, de un principio espiritual propio $y$, al igual que los humanos, presentan características sociales como vivir en comunidad, tener lenguaje, acatar reglas de parentesco, desarrollar actividades tecnológicas, rituales, etc. Esta humanidad generalizada hace que la gente establezca con otros seres vínculos personales de todo tipo: amistad, filiación, enemistad, seducción o intercambio. Sin embargo, debido a diferencias en su fisicalidad, las personas humanas y no humanas aprehenden el mundo de acuerdo a un punto de vista propio: las herramientas biológicas que le permiten ocupar un hábitat determinado hacen que las características de su entorno que resulten relevantes sean aquellas que estén orientadas a su propia corporalidad (modos de locomoción, adquisición de alimentos, etc.) (Descola, 2011, 2014; para una discusión más amplia sobre animismo ver entre otros Bird-David, 1999; Ingold, 2000 y trabajos compilados en Harvey, 2014).

Viveiros de Castro (2004a, 2004b) ha propuesto un modo diferente de salir del "corset" del dualismo cartesiano, a través de la teoría del perspectivismo multinaturalista. La mitología entre muchos grupos amerindios, especialmente los amazónicos, describe un estado inicial de no diferenciación entre animales y humanos. El estado actual de las cosas no se generó, como en el pensamiento occidental, a través de una humanidad que se separa del sustrato común de la naturaleza, sino que, inversamente, la separación entre humanos y animales partió de un estado común de humanidad, a partir del cual los animales adquirieron otras formas y cuerpos. Pese a su apariencia, los animales (al igual que varios otros seres, como espíritus, muertos, plantas y algunos objetos) continúan siendo humanos, tal como para nosotros, los humanos continuamos siendo, "en el fondo", animales. Esta forma humana interna corresponde al alma o espíritu de los animales, que les otorga subjetividad e intencionalidad y los califica como personas. Por otra parte, la forma corporal externa que los humanos percibimos de los animales es descrita a menudo como un "ropaje" o piel por encima de su forma interna; esta última solo puede ser percibida por seres de su misma clase o por entidades "transespecíficas" (por ej. chamanes) (Viveiros de Castro, 2004a).

El punto clave del perspectivismo es que las distintas clases de personas -humanas y no humanas- aprehenden la realidad desde diferentes puntos de vista. Así, el modo en que los humanos ven a los animales es distinto del modo en que estos últimos ven a los humanos y a sí mismos. Los espíritus y los animales predadores se ven 
a sí mismos como humanos y ven a los humanos como animales (presas), mientras que los animales cazados por los humanos ven a estos últimos como animales predadores o espíritus. En sus propias aldeas y casas, los animales viven vidas humanas: comen las mismas comidas, usan los mismos adornos (que nosotros vemos como plumas, pelaje, picos, etc.) y tienen la misma forma de organización social (Viveiros de Castro, 2004a). En definitiva, todos los distintos tipos de seres ven sus aspectos corporales y de comportamiento en forma de cultura humana. La posesión de un alma similar implica la posesión de conceptos similares, que determina que todos vean las cosas de la misma manera. Lo que cambia al pasar de un tipo de sujeto a otro no son los conceptos que se aplican a las cosas, sino los referentes de los conceptos; por ejemplo, donde las personas humanas ven sangre, los yaguaretés ven chicha de mandioca. Las diferencias de perspectiva no son "una pluralidad de puntos de vista de un mundo único, sino una visión única de mundos diferentes" (Viveiros de Castro, 2004b: 6). Así, las distintas perspectivas no están dadas por la mente o el espíritu (que es indiferenciado y siempre percibe lo mismo) sino por la especificidad de los cuerpos: este es el elemento particularizador. El cuerpo no refiere meramente a un sustrato físico, sino a un conjunto de afecciones o formas de ser que constituyen un habitus; las disposiciones, capacidades y dispositivos anatómicos que habilitan un modo de vida. La forma externa de un cuerpo puede ser un buen signo de sus capacidades de afección; sin embargo, las apariencias siempre son engañosas: una forma humana, por ejemplo, puede estar ocultando la afección de un yaguareté (Viveiros de Castro, 2004a).

Hay varios desdoblamientos de este complejo de ideas. Primero, como se señaló previamente, las personas humanas no pueden ver espontáneamente a los no humanos como personas: su subjetividad se considera un aspecto no evidente. Si esto sucediera se corre el peligro de ser dominado por esa subjetividad, pasar a su lado y transformarse en un animal, un muerto o un espíritu. Sin embargo, ciertos seres como los chamanes, tienen la capacidad de adoptar la perspectiva de otros seres no-humanos y verlos de la misma manera que ellos se ven a sí mismos (o sea, como humanos). Así, pueden traspasar deliberadamente las barreras ontológicas y volver para contarlo; de allí su función como interlocutores en diálogos transespecíficos. Segundo, este cambio de perspectivas es posible gracias a un proceso de metamorfosis que no ocurre en el plano del espíritu (como en la conversión religiosa, por ejemplo) sino a nivel material. Al mismo tiempo que el cuerpo es el principal elemento diferenciador, está sometido a una inherente transformabilidad. La metamorfosis interespecífica de los cuerpos es un hecho natural: los espíritus, los muertos y los humanos pueden asumir forma animal, o una especie animal convertirse en otra. Así, los chamanes pueden ver a los animales como personas porque pueden utilizar su "ropaje" y de esta forma transformarse en animales
(Viveiros de Castro, 2004a). Tercero, se desprende de lo anterior que la transformación se concibe en términos de intercambio (de perspectivas); implica un involucramiento mutuo entre seres humanos y no humanos, mediante la in-corporación, al propio ser, del punto de vista del otro. El lenguaje de estos procesos de subjetivación es el de la predación ontológica. Cuarto, la "personitud" y la "perspectividad" -la capacidad de ocupar un punto de vista- es una cuestión de grado y de contexto más que una propiedad absoluta. Las cosmologías amazónicas no atribuyen subjetividad (o el mismo grado de subjetividad) a todos los seres; por el contrario, existe una escala que está comúnmente ligada a la cadena trófica: los seres más poderosos se encuentran en su cúspide (por ejemplo, los grandes predadores). Las reglas alimentarias están ligadas a la escala de potencia espiritual de los animales (Århem, 1996; Fausto, 2007; Politis y Saunders, 2002; Viveiros de Castro, 2004a).

En síntesis, el perspectivismo contrasta netamente con el pensamiento occidental, que considera que existe una única naturaleza, con sus leyes universales, y una diversidad de culturas, con múltiples representaciones sobre la misma realidad externa. De esta forma, los problemas ontológicos se reducen a cuestiones epistemológicas. El perspectivismo postula en cambio que lo universal es el elemento subjetivo, el alma humana, mientras que la naturaleza del cuerpo reviste el carácter de lo particular. Existe entonces una cultura y múltiples naturalezas, una unidad representativa aplicada a una diversidad radical real, una epistemología constante y múltiples ontologías, el mismo significado y múltiples referentes (Viveiros de Castro, 2004b). Entre las principales implicancias de estas ideas podemos resaltar que: a) implica una ampliación de lo que normalmente consideramos como "lo social". Las personas humanas no pertenecen a un dominio ontológico separado; la atribución de subjetividad, intencionalidad y agencia a los animales y otros seres lleva a reconsiderar todos los fenómenos que potencialmente comprenden o implican relaciones sociales. b) Es una ontología profundamente relacional. Para occidente, un concepto como "sangre" se aplica a un objeto en virtud de sus propiedades intrínsecas. En el perspectivismo, en cambio, se define relacionalmente, de una forma similar a un término de parentesco como "hermana". Yo puedo ser hermana de alguien porque existe un otro para quien soy hermana. A su vez, quien es hermano para mí es esposo para mi cuñada, de la misma manera que lo que es sangre para mí es cerveza de mandioca para el yaguareté. Algo es en virtud de su relación con algo más: no existe "hermana" como un ente trascendental sobre el que luego tenemos diferentes visiones. c) En relación con esto, es una teoría no representacionalista. Lo que cambia al pasar de un ser a otro no son las "visiones del mundo" ya que las representaciones son una propiedad del espíritu, que es constante; las diferencias están dadas por la especificidad de los cuerpos. d) Así, el perspectivismo destaca la 
materialidad del cuerpo como asiento de la afección, las capacidades de afectar y ser afectados por otros cuerpos. e) Estos están sometidos a una constante transformación: son ropajes que a menudo pueden cambiarse; la materia es inherentemente inestable.

De acuerdo con Viveiros de Castro (2003, 2010), el perspectivismo no sería un tipo o subtipo de animismo en el sentido de Descola (2011, 2014), ni un esquema de práctica, sino un concepto, una teoría, otra antropología por derecho propio: el punto de vista nativo sobre el concepto de punto de vista. Más que intentar clasificar ontologías, el perspectivismo se pregunta: ¿qué pasa cuando el clasificado se vuelve clasificador? En lugar de partir de un problema universal "natural" (por ej., el concepto antropológico de "lo social") y determinar sus diferentes soluciones "culturales" (la representación indígena) se trata de determinar qué constituye "lo social" para el objeto de estudio. Así, los verdaderos objetos de la antropología no son epistemologías sino ontologías. Pensar las teorías nativas como epistemologías implica reducirlas a creencias o cosmovisiones sobre el mundo, un mundo cuyos términos están definidos, en última instancia, por la ontología occidental. De esta manera, el autor invita a "tomar en serio" el discurso del nativo; este habla de algo más que de sus propias creencias: habla del mundo (Viveiros de Castro, 2002, 2003). No se trata de intentar explicarlo o interpretarlo, sino utilizarlo para modificar los términos del debate antropológico en su conjunto, dándole igualdad de derecho con respecto al discurso antropológico. Esto significa entender la antropología como una práctica orientada a legitimar y poner en valor el pensamiento "salvaje", indómito, insurrecto, que trabaja para contribuir a la "autodeterminación conceptual" (ontológica) de los otros; en fin, una forma de descolonizar el pensamiento (Viveiros de Castro, 2003).

El perspectivismo converge en varios de sus puntos centrales con recientes vertientes teóricas de la arqueología que, inspiradas más bien en la filosofía occidental, han reorientado su foco de interés desde preguntas de carácter epistemológico (¿cuál es el carácter del conocimiento arqueológico? ¿cómo representaban el mundo las personas en el pasado? ¿cómo podemos nosotros interpretar, "leer" o traducir esos significados a partir del trabajo arqueológico?) a otras de naturaleza ontológica (¿qué son las entidades arqueológicas? y ¿cuál es el carácter real de la práctica arqueológica?) (Alberti, 2016; Fowler, 2004; Harris, 2018; Jones y Alberti, 2013; Olsen y Witmore, 2015). Estos enfoques han desafiado los dualismos cartesianos, destronando al humano como único agente con capacidad de acción. Más bien, consideran a los seres humanos como entrelazados con cosas y entidades otras-que-humanas (animales, montañas y cosas de todo tipo), ninguna de las cuales tiene existencia independiente de las otras ni prominencia ontológica sobre las demás y que constituyen, todas ellas, agencias activas y coproductoras del mundo. Estos "tejidos", que con distintos matices se han conceptualizado como redes (Latour, 2005), mallas (Ingold, 2012) o ensambles (Harris, 2018) permiten comprender cómo las distintas entidades del mundo son hechas y desechas, materializadas y desmaterializadas en un proceso continuo en el que no existen esencias fijas, sino cosas que emergen a partir de interrelaciones contextual e históricamente situadas. Es a partir de este entretejido activo, productivo y continuo que los mundos emergen. Estas ontologías relacionales, entonces, rechazan cualquier idea de sustancias fijas preexistentes; las cosas no pueden ser definidas a priori a partir de un conjunto de cualidades esenciales inherentes, sino que las cosas existen y sus propiedades emergen a partir de un continuo proceso relacional. Se trata, por tanto, de un mundo en constante devenir y flujo (Conneller, 2011; Ingold, 2012). En este enfoque, que puede entenderse como un "animismo teórico occidental" (Alberti y Marshall, 2009), la materia no se considera más un sustrato inerte al que el humano "añade" significado, sino como animada e imbuida de vitalidad.

\section{¿Representaciones? de animales en la cerámica Goya-Malabrigo}

Los apéndices zoomorfos característicos del estilo cerámico de Goya-Malabrigo han sido asociados a la influencia amazónica sobre el Paraná Medio e Inferior, más específicamente a la expansión arawak (por ej. Serrano, 1950; Torres, 1911), idea que ha sido retomada en los últimos tiempos (ver discusión en Politis y Bonomo, 2018). Consisten en modelados que pueden ser bidimensionales, a la manera de siluetas recortadas sobre la pared de la vasija, o bien adquirir forma tridimensional, ya sea macizos, huecos o "tubulares". Comúnmente se modelaron solo las cabezas de los animales, aunque en ocasiones se esquematizaron también las alas, colas y patas, o se representaron animales completos. Se encuentran en fuentes, platos, cuencos o en ollas globulares, ya sea cerca del borde -muchas veces en actitud de asomarse al interior del recipiente- o bien en el cuerpo de las vasijas, a modo de asas (Caggiano, 1984; Ceruti, 2003; Politis y Bonomo, 2018; Serrano, 1950, entre otros). Un número importante de apéndices, de mayor tamaño, se encuentran en artefactos de función desconocida, denominados en la literatura regional como "campanas": cuerpos con forma acampanada o cilíndrica, abiertos en su base, y con uno o dos orificios laterales o cuspidales (Gaspary, 1950). Estas peculiares piezas se han interpretado de diversas maneras, ya sea como sahumadores, braceros o, en forma más general, como artefactos "ceremoniales". Se hallan frecuentemente asociadas a entierros humanos, aunque también se han recuperado en contextos domésticos (Gaspary, 1950; Serrano, 1950; Torres, 1911, entre otros) (Figura 1 a).

Desde que los apéndices zoomorfos son conocidos, ha 
existido un interés por reconocer las distintas especies de animales que han sido modeladas (Caggiano, 1984; Ceruti, 2003; Serrano, 1950, entre otros). Más recientemente, Ottalagano $(2008,2010)$ ha puntualizado en las representaciones de aves, particularmente de psitaciformes, desde una perspectiva simbólica del arte mobiliar cerámico, entendiéndolo como una forma de expresión de los modos compartidos de percibir y entender el mundo. En este sentido, resaltó que la naturaleza constituye una importante fuente de significados para las sociedades y que algunos animales en particular, en virtud de sus características morfológicas y etológicas, constituyen recursos metafóricos de singular potencia. De acuerdo con la autora, esto podría explicar la extensión -no solo en el caso Goya-Malabrigo sino entre numerosos grupos de las tierras bajas, como los del Gran Chaco- del "simbolismo" de las aves, particularmente los psitácidos, que se destacan por sus habilidades cognitivas, sus cualidades estéticas, su capacidad de vuelo, entre otras características (Ottalagano, 2007, 2008). Como forma de aproximación a esta temática, ha compilado información histórica y etnográfica sobre la importancia de las aves en la mitología de los grupos guaycurúes y mataco-mataguayos, en la cual estos animales se relacionan fuertemente con la transformación chamánica y con la metamorfosis de las personas humanas luego de su muerte, además de que aparecen frecuentemente vinculadas a roles de mensajeras y vigías, como creadoras de la humanidad y dadoras de bienes culturales, o como productoras de fenómenos atmosféricos (Ottalagano, 2007; para ejemplos similares sobre el rol de las aves, referidos a casos amazónicos, ver Walker, 2010). Por su parte, Cornero (2019) ha estudiado los modelados de catártidos, proponiendo su asignación al cóndor (Vultur gryphus), un ave sagrada para el mundo andino. A partir de ello, propuso vínculos con esta región, no solo a través de redes de intercambio, sino también a nivel de las cosmovisiones. También ha provisto novedosas y sugestivas interpretaciones para algunos de los modelados que tradicionalmente se han interpretado como psitácidos, proponiendo que se trataría, en cambio, de seres que combinan la figura de un pez, en la parte superior, fusionado en su línea ventral al pico del loro (Cornero, 2018) (Figura 1 b).

Recientemente, Bonomo y colaboradores (2020), examinaron un amplio conjunto de apéndices ( $n=$ 483) provenientes de excavaciones propias y de colecciones de museos o privadas. La mayoría de ellos se encuentran fragmentados, es decir, separados de las vasijas que integraban, aunque en algunos casos mantenían su conexión con parte del borde o la pared de los contenedores originales, o formaban parte de piezas enteras. Los autores analizaron la diversidad de animales representados en los apéndices, que fueron identificados mediante el examen de rasgos anatómicos específicos elaborados mediante modelado, pastillaje y/o incisión. Encontraron una amplia predominancia de las aves $(n=300)$, entre las que pudieron identificarse principalmente psitácidos (loros y guacamayos, $n=114$ ) $y$, en segundo lugar, aves rapaces $(n=38)$, como el águila harpía (Harpia harpyja), el carancho (Caracara plancus), el jote real (Sarcoramphus papa), el cóndor andino (Vultur gryphus) y varios búhos (Strigidae). Además, identificaron algunas representaciones de patos (Anatidae), flamenco (Phoenicopterus sp.) y Passeriformes. Entre los mamíferos se destacan por su abundancia el carpincho (Hydrochoerus hydrochaeris, $\mathrm{n}=12)$ y los carnívoros ( $\mathrm{n}=15)$, especialmente el yaguareté (Panthera onca), aunque también se identificaron cánidos (cf. Canis familiaris) y lobito de río (Lontra longicaudis) (Figura $1 \mathrm{c}-\mathrm{d}$ ). Otros mamíferos que se reconocieron son: murciélago vampiro (Desmodus rotundus), tapir (Tapirus terrestris), armadillos (Dasypodidae), monos (Atelidae) y camélidos (Camelidae). En menor medida se identificaron reptiles $(n=10)$, particularmente el yacaré (Caimaninae), lagartos y serpientes, entre estas últimas, la gran anaconda curiyú (Eunectes notaeus). También hay escasos modelados de anfibios (Anura, $n=4$ ) y diversos moluscos gasterópodos ( $n=9$, por ejemplo, Pomacea spp.). En algunos casos se destacaron aspectos del movimiento y la etología de los animales: serpientes enroscadas en posición de ataque o loros que presentan los copetes encrespados (como en los momentos de excitación) y las bocas bien abiertas, como gritando, $u$ otros representando fases de vuelo. Finalmente, los modelados de personas humanas también están presentes en la cerámica y, así como en los animales se enfatizó la representación de los ornamentos corporales (por ej. plumaje, manchas de la piel), los apéndices antropomorfos muestran el uso de peinados, tocados, plumas, vinchas, orejas perforadas y tatuajes o pinturas faciales (Bonomo et al., 2020).

Al examinar el tipo de animales que fueron modelados en la alfarería, lo primero que llama la atención son las características de su corporalidad, no en el sentido de atributos físicos externos sino como conjunto de capacidades y disposiciones que determinan la particularidad de cada cuerpo y sus formas de afección (cómo se mueve, cómo se comunica, qué come, etc.) (Viveiros de Castro, 2004a). Así, como han señalado Bonomo y colaboradores (2020), los loros, para tomar un caso emblemático, presentan una serie de características etológicas que permiten trazar analogías con las personas humanas: viven en grupos familiares con algún tipo de organización social, tienen parejas estables que comparten sus nidos durante años, cooperan con gran dedicación para el cuidado de las crías, tienen sonidos específicos asociados que fungen como "nombres" y tienen la capacidad de imitar el habla humana. También se privilegió la representación de aves rapaces, que cazan o bien se alimentan de carroña (buitres, águilas, búhos). Un criterio similar parece haber operado en el caso de los mamíferos y los reptiles, entre los que es frecuente la representación de grandes depredadores (por ej. yaguareté, yacaré, anaconda). Muchos de estos animales 


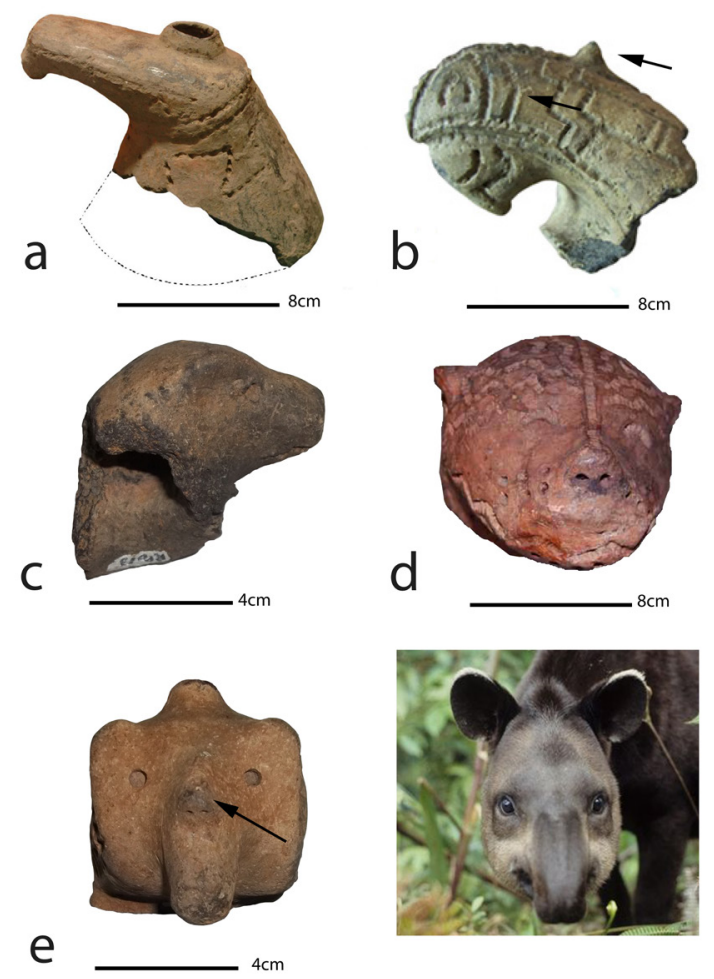

Figura 1. Apéndices zoomorfos en cerámica Goya-Malabrigo. (a) Campana recuperada en el sitio Los Tres Cerros 1 (departamento Victoria, Entre Ríos), modificado de Di Prado, 2015. (b) "Pez-loro" procedente de las islas de San Javier (Santa Fe), modificado de Cornero, 2018; las flechas indican lo que la autora interpreta como opérculos y aleta. (c) Modelado de carnívoro (posible lobito de río) depositado en la colección del Museo de Conscripto Bernardi (departamento Federal, Entre Ríos). (d) Modelado de yaguareté, procedente de las islas de Victoria; modificado de Bonomo, 2012. (e) Modelado depositado en la colección del Museo de Conscripto Bernardi (departamento Federal, Entre Ríos); obsérvese la nariz humana asociada a rasgos similares a la probóscide y la cresta sagital de Tapirus terrestris.

Figure 1. Goya-Malabrigo pottery with zoomorphic appendages. (a) Bell from Los Tres Cerros 1 site (Victoria department, Entre Ríos), modified from Di Prado, 2015. (b) "Fish-parrot" recovered at San Javier islands (Santa Fe), modified from Cornero, 2018; arrows show what was interpreted by the author as the fish operculum and dorsal fin. (c) Carnivore appendage (possibly neotropical otter) deposited in the collection of Conscripto Bernardi Museum (Federal department, Entre Ríos). (d) Jaguar appendage from Victoria islands; modified from Bonomo, 2012. (e) Appendage deposited in the collection of Conscripto Bernardi Museum (Federal department, Entre Ríos) showing a human nose and attributes similar to the Tapirus terrestris proboscis and sagittal crest.

representan un peligro para los humanos; varios tienen hábitos nocturnos (félidos, armadillos, murciélagos, búhos) y/o son los animales más grandes de su grupo (carpinchos, buitres, yaguaretés, anaconda) (Bonomo et al., 2020).

Lo segundo que llama la atención es el marcado contraste entre los animales que fueron modelados en la alfarería y aquellos que aparecen representados entre los restos de alimentación. Las prácticas de subsistencia inferidas para los sitios Goya-Malabrigo a lo largo del Paraná se orientaron eminentemente hacia la pesca y la caza de mamíferos de hábitos acuáticos o semiacuáticos, sobre todo roedores -fundamentalmente coipo (Myocastor coypus) y, en menor medida, carpincho (Hydrochoerus hydrochaeris)- y ciervo de los pantanos (Blastocerus dichotomus) (Bastourre, 2013, 2014; Bonomo et al., 2014; Caggiano, 1984; Ceruti, 2003, entre otros). A excepción del carpincho, ninguna de estas especies fue identificada en los apéndices (Bonomo et al., 2020). Inversamente, las aves, tan frecuentemente modeladas en la alfarería, son muy escasas en los conjuntos arqueofaunísticos. Las especies que fueron aprovechadas para el consumo son mayormente aves acuáticas de gran porte y/o hábitos gregarios, como macaes, cigüeñas, biguá, garzas, patos y gallaretas (Bastourre, 2013), que casi no están representadas en los apéndices. Los loros, las aves rapaces, los carnívoros (cánidos, félidos, mustélidos), los monos, las serpientes y otros animales modelados en la cerámica, no suelen ser identificados en los conjuntos arqueofaunísticos. En los casos en que sus restos óseos son recuperados (por ej. carnívoros), no están asociados claramente a actividades culinarias, sino que aparecen en contextos funerarios, o relacionados con la producción de instrumentos u objetos ornamentales (Bastourre, 2014; Bonomo et al., 2014; Caggiano, 1984; Schmitz et al., 1972; Serrano, 1950).

Las características de los animales que fueron modelados, y el hecho de que los animales consumidos como alimentos se encuentren subrepresentados en la cerámica (y viceversa) no responde al azar, sino que probablemente da cuenta de un "filtro ontológico", en los términos de Descola (2011, 2014), más cercano a un régimen animista o perspectivista. Las cualidades de los animales que las personas humanas actualizaron en la cerámica, derivadas del encuentro práctico con las distintas agencias del entorno, siguen un criterio de selección similar al que muchas otras sociedades de tierras bajas aplican a la hora de clasificar los tipos de seres en el mundo (ver, entre otros ejemplos, el caso Achuar, en Descola, 1988; Makuna, en Århem, 1996; Kashinawá y Miraña, en Fausto, 2007; y Nukak, en Politis y Saunders, 2002). Como adelantamos previamente, en estas ontologías la posesión de "alma" es una cuestión de grado y no de esencia; la capacidad de agencia está desigualmente distribuida entre los seres en el mundo. Muy frecuentemente, la cadena alimentaria suele ser un índice de "agentividad". En Amazonía, los grandes predadores como el yaguareté y la anaconda ocupan la cúspide de esta jerarquía, mientras que los peces y las plantas suelen ubicarse en la base. Asimismo, las plantas (con varias excepciones, como las psicoactivas) poseen menos agencia que los animales, y los herbívoros, en general, menos que los carnívoros (Fausto, 2007). Sin 
embargo, hay importantes variaciones, ligadas no solo a la alimentación sino a características relacionadas con el color, tamaño, etología, entre otras. Significativamente, el comportamiento de apareamiento y la capacidad de vocalización e imitación de las aves también han sido señaladas como indicadores de potencia subjetiva (Fausto, 2001). Esto da lugar a una serie de restricciones alimentarias y de precauciones cuyo alcance se relaciona con la escala de agencia de las distintas categorías de animales. Su violación, conlleva el riesgo de contraer una enfermedad, concebida como una contrapredación llevada a cabo por el espíritu de la presa (ahora convertida en predador), en una dinámica de inversión de perspectivas que lleva a la persona humana a convertirse en animal (Viveiros de Castro, 2004a). De esta forma, es factible que los animales representados en la alfarería, cuyos restos óseos no suelen encontrarse en los sitios arqueológicos, hayan estado sujetos a algún tipo de tabú alimentario total o parcial (Bonomo et al., 2020). Un caso no tan claro es el del carpincho, que fue frecuentemente consumido y también modelado. Es posible que estos animales hayan tenido un estatus más ambivalente, similar por ejemplo al del pecarí entre muchas sociedades amazónicas (ver por ejemplo el caso Nukak, Politis y Saunders, 2002). La caza de estos últimos es distinta a la de otros animales tanto en términos técnicos como en concepción -ya que suele percibe como más cercana a la guerra, la predación hacia los enemigos- $y$, a su vez, su consumo suele requerir mayores esfuerzos de desubjetivación (Fausto, 2007, ver acápite siguiente).

No todos los modelados pueden ser referidos sin ambigüedades a alguna de las entidades que somos capaces de reconocer con las herramientas de la taxonomía biológica. Algunos de ellos, en cambio, parecen híbridos que combinan atributos de diferentes animales; por ejemplo, figuras humanas que presentan rasgos faciales que los asemejan a los de las aves, especialmente los búhos (Bonomo et al., 2020), o apéndices donde atributos humanos (por ejemplo, narices) se asocian a rasgos de difícil identificación (Figura 1 e) (ver otros ejemplos de seres híbridos en Politis y Bonomo, 2015). Se ha planteado que estos modelados que combinan atributos antropo/ zoomorfos pueden representar estados transformativos, característicos de las prácticas chamánicas (Bonomo et al., 2020). En otros casos, la mixtura de atributos es más sutil, como ha mostrado Cornero (2018) para los denominados "peces-loros", en los que ambas especies comparten elementos (ojos, cabeza, silueta), combinando en el mismo diseño -que en apariencia representa una única figura (el loro)- un contenido doble, cuya identificación depende del cambio en el ángulo de observación (figura 1b). De esta forma, el soporte rígido de la cerámica logra captar el movimiento y la mutación. Más recientemente, la autora agregó que, en estos mismos diseños -y en algunos otros que representan distintos animales- es posible identificar perfiles humanos trazados con surco rítmico, interpuestos entre los peces y los loros, y compartiendo con estos algunos atributos anatómicos (Cornero, 2020). De forma similar a Bonomo et al. (2020), vinculó estas figuras con la transformación chamánica y señaló además que el entramado de componentes pezloro-humano expresaría un lenguaje simbólico que debe entenderse en el plano de lo mitológico, lo metafórico y lo imaginario (Cornero, 2020). Estos distintos ejemplos -que empiezan a acumularse en la arqueología del áreamuestran el carácter mixto, polimórfico e inestable de varios de los modelados cerámicos, de acuerdo con la lógica de la transformación interespecífica propia del pensamiento amerindio, en el que las apariencias son siempre engañosas.

Lo expuesto hasta aquí puede encuadrarse dentro de lo que Alberti (2016) caracteriza como un uso analógico del animismo y el perspectivismo, que apunta a caracterizar los regímenes ontológicos que pudieron haber operado en el pasado. Esta aproximación, sin embargo, corre el riesgo de reducir la cuestión ontológica a un problema epistemológico, sobre la forma en que las personas representan "el" mundo. Una interpretación representacionalista de los modelados zoomorfos es contraria a la propia lógica de la teoría perspectivista, porque impone una separación entre las cosas y sus significados (Alberti y Marshall, 2009). El significado aparece como algo que el sujeto humano "adhiere" a la cosa material, pero que es en primera instancia distinto a la cosa en sí misma; las cosas, de esta forma, solo interesan en la medida en que re-presentan un concepto pre-existente que emana del sujeto humano. Un giro ontológico más crítico, en cambio, debería apuntar a utilizar las teorías indígenas como una fuente de conceptos sobre lo que el/los mundo/s son. Desde esta perspectiva, ya no se trata de lo que los apéndices zoomorfos "representan": qué tipo de animales simbolizan y qué tipo de "visión de mundo" expresan. En cambio, las representaciones pueden entenderse más bien como presentaciones, ya que son en sí mismas performativas: no solo expresan el mundo sino que son agentes de su producción (Anderson y Harrison, 2010). Las vasijas con apéndices zoomorfos no solo "portan" un significado relacionado con la concepción de los animales, sino que pueden pensarse como cosas-concepto. Henare et al. (2007) explican esta idea a través del ejemplo clásico del "polvo-poder" aché: no se trata de una cosa (polvo) que se considera poderosa, esto es, una sustancia inerte a la que las personas dan un significado, sino que el polvo es poder (y viceversa); ambos son una y la misma cosa, no pueden pensarse separadamente. De forma similar a la noción de vasija-cuerpo de Alberti y Marshall (2009), podemos pensar en las campanas, las ollas y los platos con modelados zoomorfos de Goya-Malabrigo como cosas en las que la idea de animalidad está inextricablemente asociada a la alfarería.

Al ser consultado sobre las campanas en los contextos funerarios, Blas Jaime, último hablante de la lengua 
chaná y divulgador de la historia oral de estos pueblos, explicó que:
“...había una leyenda de que el loro había sido una persona que era muy habladora, y por hablar no hizo bien su guardia (...) fue castigado convertido en ave" (...) "Por eso tuvieron desarrollado la cultura de las campanas, con las cabezas de loro (...). Y ellos creían que haciendo esas cabezas de loro de cerámica, poniéndolas sobre las tumbas de los muertos el espíritu venía a ese lugar: ndorí (?), donde estaban los muertos y se iba a entretener hablando con esa cabeza de loro. Se ponía a hablar y no molestaba a ellos..." (Ottalagano y Colobig, 2010: 93-94).

Hay varios interesantes elementos en este relato. En primer lugar, la referencia a un pasado mítico de humanidad indiferenciada a partir de la cual se diferenciaron las formas animales, en este caso los loros. El segundo es la conexión entre estos últimos y los muertos, que remite a la noción, ampliamente reportada en la literatura etnográfica, de que los espíritus de los difuntos pueden manifestarse bajo la forma de animales, frecuentemente aves: como toda metamorfosis, la muerte es una alteración de la apariencia manifiesta (ver los ejemplos mencionados anteriormente en Ottalagano, 2007 y Walker, 2010). El tercero es la relación material que se establece entre las cabezas de loro de cerámica y la capacidad de comunicación de los propios loros, como si el modelado de las cabezas habilitara la manifestación de una de las características más distintivas del estilo de vida de estas aves, el habla. Es significativo que sea también el pico -el dispositivo anatómico vinculado a esta actividad- el elemento más invariablemente utilizado por los investigadores para diferenciar las cerámicas como loros, incluso en los modelados más "estilizados" o simplificados. En este contexto, el modelado de la cerámica, más que intentar reproducir o representar los atributos de los animales, es una forma de marcar o especificar determinadas afecciones. La "agencia" de estas campanas puede entenderse entonces como el resultado de las relaciones que producen la diferenciación de formas materiales específicas; cabe aclarar: relaciones entre animales, alfareros/as, arcillas y demás participantes, incluidos los/as arqueólogos/as, ninguno de los cuales es preexistente al "impulso diferenciador" del que participan (Alberti y Marshall, 2009). Finalmente, el relato de Blas Jaime muestra que las campanas pueden comunicarse con los espíritus debido a que poseen un punto de vista que, justamente, es diferente al de las personas humanas, que no son capaces de ver este tipo de entidades; de ahí su función de "protectores", ya que podían hablarles y distraerlos. A diferencia del pensamiento occidental, en donde los puntos de vista emanan del sujeto, en el perspectivismo el punto de vista crea al sujeto: todo lo que tiene punto de vista cuenta como sujeto (Viveiros de Castro, 2004a). Aquí, es interesante recordar que las cabezas de cerámica son, esencialmente, rostros; los rasgos faciales de los animales son lo que principalmente se modela en la cerámica. Ingold (2000: 124) señala que el rostro tiene una propiedad muy peculiar: es el lugar desde donde vemos el mundo y, al mismo tiempo, si bien todos los demás pueden ver nuestra cara, esta permanece invisible para nosotros mismos. El rostro es la apariencia visible, a los ojos de los otros, de nuestra propia presencia subjetiva como agentes de percepción; es la forma del "otro como sujeto" con punto de vista. Pero "otro" se define relacionalmente, por lo que para todo otro siempre hay un otro para el que "otro" es alguien más (Viveiros de Castro, 2010): las campanas pueden ser sujetos porque son otros para los espíritus.

La vitalidad inherente a las vasijas-animales en el pasado prehispánico se pone de manifiesto en la existencia, de acuerdo con Cornero (2018), de cerámicas "matadas", apéndices con impactos de percusión intencionales, ubicados recurrentemente en determinados sectores de las cabezas. Así, puede pensarse en estos golpes como probablemente dirigidos a neutralizar la potencia subjetiva de estos seres. Por otra parte, la elevada fragmentación que presenta la cerámica en la región también ha sido interpretada por algunos autores como el resultado de la rotura intencional, de carácter ritual, de las vasijas (por ej. Torres, 2011; Ceruti, 2003), lo que podría dar cuenta de ciclos vitales similares a los de otros seres animados (Bonomo et al., 2020) ${ }^{1}$.

¿Cómo podemos dar entidad a estas vasijas-animales? ¿Cómo podemos "tomar en serio" estas campanasloros que hablan con espíritus, sin reducirlas a creencias exóticas sobre el mundo? ¿Cómo pueden ser una fuente de nuevas comprensiones sobre lo que los mundos son? En lugar de pensarlos a priori como objetos que portan algún significado distinto de sí mismos, el cual debemos desentrañar, podemos pensar desde las cosas (Henare et al., 2007), centrándonos en lo que su presencia material provoca en el mundo. Animar estos objetos de esta manera significa enfocarse, no en lo que estos representan, sino en lo que estos son y en su capacidad de afección, no solo en el pasado sino también en quienes los estudiamos. De acuerdo con Alberti (2016), el involucramiento activo con los materiales y una actitud de apertura y asombro son elementos clave para permitir que las cosas puedan afectarnos y que sean ellas mismas las que nos conduzcan a las posibilidades de nuevos mundos. Ese extrañamiento es fundamental para revelar y sostener la alteridad de las cosas arqueológicas, como cosas que "no tienen sentido ontológicamente", que escapan a marcos interpretativos cerrados. En este sentido, las teorías indígenas, además de una fuente de analogías, brindan herramientas para reconfigurar

\footnotetext{
$1 \mathrm{Si}$ bien esta idea es atractiva, la fragmentación cerámica en la región puede tener múltiples causas (por ej. aspectos tafonómicos, reutilización de la cerámica como material constructivo en los cerritos) y la importancia relativa de cada una de ellas aun no es completamente comprendida.
} 
conceptos y prácticas arqueológicas, ayudándonos a que puedan emerger novedades de las cosas que estudiamos y pasados materialmente diferentes.

Como expresamos previamente, en la teoría perspectivista el asiento de la afección está en la materia, en los cuerpos, y estos son ontológicamente inestables. El foco entonces pasa a estar en el problema de la transformación de los cuerpos: si la materia es inherentemente inestable, ¿cómo son los cuerpos especificados? y esos cuerpos ¿qué mundos traen a la existencia? Los apéndices zoomorfos no solo estuvieron presentes en los contextos funerarios, sino que conformaron ollas, platos y fuentes, formando parte de la producción y consumo de alimentos. Cabe preguntarse, entonces, qué pudo implicar este involucramiento entre animales y humanos en contextos de comensalidad.

\section{La transformación de los cuerpos: comensalidad y predación ontológica}

Una de las más importantes formas de transformación de los cuerpos son las transformaciones culinarias, entendidas como el conjunto de operaciones mediante las cuales los recursos -en este caso, animales- son convertidos en productos socialmente comestibles. A partir del estudio de los perfiles anatómicos de los conjuntos arquefaunísticos de sitios Goya-Malabrigo del Delta del Paraná y el análisis de las huellas de corte, la termoalteración y la fragmentación, entre otras modificaciones, hemos podido reconstruir las distintas actividades involucradas en el procesamiento y la cocción de estos recursos (procesamiento por secado, hervido, asado, etc.) (por ej. Bonomo et al., 2014; Bastourre y Azpelicueta, 2020). Estas actividades son de suma importancia ya que es a través de estos procesos materiales que ocurre la especificación de los cuerpos durante las prácticas alimentarias: es en esa manipulación material que se definen las capacidades agentivas particulares de los seres involucrados (humanos, recursos, artefactos), esto es, se resuelve su estatus ontológico (Pazzarelli, 2013). Fausto (2007) ha abordado este problema mediante la siguiente pregunta: si en las sociedades de tierras bajas los animales son personas, entonces ila caza puede considerarse equivalente a la guerra y el consumo de animales ser una forma de canibalismo? El punto clave de la tesis del autor es que la predación es un vector trans-específico de la socialidad: nunca ocurre en una única dirección y siempre es un terreno en disputa. De allí la necesidad de distinguir cuidadosamente entre dos tipos diferentes de operaciones: comer cómo y con alguien (comensalidad), y, por otro lado, comer $a$ alguien en su condición de persona (consumo canibalístico) (Fausto, 2001, 2007). Como dijimos, los animales que poseen capacidades agentivas muy poderosas son considerados no comestibles, ya que su consumo implicaría la contrapredación por parte de la presa, la adquisición de sus propiedades subjetivas y la transformación de la persona humana en animal a través de una inversión de perspectivas. Sin embargo, aun las presas que se consideran comestibles pueden actuar como sujetos: la condición general no es la de objeto sino la de persona. Por ello, un consumo no canibalístico de los animales requiere un proceso de desubjetivación, en el que se remueve su agencia, esto es, su capacidad de actuar sobre el otro (i.e. su capacidad de contrapredación). Esto es logrado comúnmente mediante el tratamiento chamánico de los cuerpos animales, en el que, por ejemplo, la carne es convertida a la categoría de planta, o los mamíferos son transformados en peces; es decir, el sujeto animal se reduce a una especie menos próxima a los humanos (Fausto, 2007). Este tratamiento suele no ser suficiente: su condición subjetiva debe ser neutralizada a través de la cocción. El fuego culinario es un operador clave en la transformación del sujeto animal en objeto y la técnica precisa empleada (por ej. hervido, asado) tampoco es indiferente a tal fin. Aun así, siempre existe un peligro inminente "de poder ver el humano que acecha dentro del cuerpo del animal que se come" (Viveiros de Castro, 2004 a: 476).

La desubjetivación de los animales que son comidos es un proceso que debe ocurrir para que pueda producirse la identificación entre los comensales (Fausto, 2007). El compartir comida y los códigos culinarios son vectores primarios de la creación de identidad. Comer con alguien y como alguien es fundamental para la fabricación de personas de la misma "especie" o, dicho de otra manera, cuerpos de la misma clase. Los regímenes alimentarios y los modos culinarios tienen un peso muy importante en las categorías de identidad (individuales, colectivas, étnicas) ya que son parte de los procesos materiales que constituyen y diferencian los cuerpos (Viveiros de Castro, 2018). Así, la comensalidad dentro de la esfera doméstica - esto es, el compartir comida en el día a día entre quienes viven en próxima cercanía- no solo caracteriza las relaciones entre parientes, sino que produce parientes. Vilaça (2002) mostró cómo esta condición no está garantizada por nacimiento, sino que tiene que ser continuamente producida mediante un proceso de fabricación de cuerpos similares y que esta consustancialidad es lograda principalmente a través de intercambios de sustancias (alimentos, fluidos corporales, sexuales). Este proceso está en permanente disputa con otras subjetividades, por lo que las relaciones de identificación no se generan únicamente entre personas humanas. En un mundo altamente transformacional, con múltiples potencialidades de existencia, distintos seres -humanos o no humanos, vivos y muertos- buscan capturar a otras personas para convertirlas en "parientes", en seres del mismo tipo, con las disposiciones y afecciones distintivas de la "especie" captora. La comensalidad juega un rol fundamental en ese proceso, como lo muestran los distintos relatos amazónicos sobre personas humanas capturadas por animales, que se convirtieron gradualmente en uno de ellos al beber su cerveza, comer su comida y participar en sus danzas: la aceptación 
de la comida de alguien lleva a una transformación que desemboca en la identificación con ese alguien. Al modificar el cuerpo a través de la alimentación, los cambios de hábitos y el establecimiento de relaciones sociales con otros sujetos, se adquiere otro punto de vista. Se conoce como "familiarización" a este proceso de convertir a otros en "iguales" (Fausto, 2007; Vilaça, 2002). Este mismo proceso opera en la mascotización, al punto que, en ciertos grupos, los términos "alimentar" y "domesticar" son equivalentes (Fausto, 2007). Entre las sociedades de tierras bajas es muy común la captura de animales jóvenes, que son adoptados, alimentados (incluso amamantados) y producidos como nuevos sujetos (parientes) dentro del dominio familiar (Erikson, 2000). En este sentido, es interesante notar que las fuentes etnográficas muestran que los psitácidos son uno de los principales animales mantenidos como mascotas y se ha sugerido que este podría ser también el caso en el área de estudio (Bonomo et al., 2020).

En este marco ¿cómo podemos entender las vasijas con apéndices zoomorfos que formaron parte de los contextos de comensalidad? Estos materiales fueron una parte integral de la producción, el servicio y el consumo de alimentos. Hemos pensado en la posibilidad de materiales en los que la noción de vasija y animalidad son inseparables. Si el concepto de familiarización abarca animales, humanos y otros potenciales sujetos, ¿puede entonces extenderse también a las vasijas zoomorfas? Como en otros cuerpos, las vasijas también se transformaron materialmente durante los procesos culinarios y participaron de la circulación de sustancias alimenticias, vital en el proceso de familiarización y consustanciación. De esta forma, cabe pensar que las vasijas-animales integraron un tejido de familiarización mediante el cual estos seres "otros" se produjeron como "semejantes". Comer con estos seres pudo ser una forma de producir socialidad a través de un proceso de identificación entre los participantes. Esto lleva a pensar no solo en la agencia de los alimentos y las vasijas culinarias en la producción de cuerpos humanos, sino también en cómo vasijas y alimentos se especificaron durante el mismo proceso. Por otra parte, si retomamos el relato de Blas Jaime sobre las campanas-loros en los contextos funerarios, en el que estas podían hablar con espíritus invisibles a los ojos humanos, podemos preguntarnos también por el punto de vista de las ollas y platos zoomorfos: ¿qué ven donde las personas humanas ven comida? Parafraseando a Viveiros de Castro (2004a) deberíamos preguntar no tanto cómo estas ven el mundo sino de qué mundo son el punto de vista, qué mundo se expresa a través de ellas. En este sentido, no debemos olvidar que las comidas siempre retienen un carácter ambivalente; pese a los intentos de desubjetivación mediante el tratamiento culinario y/o chamánico, siempre puede permanecer un rastro de subjetividad en el animal que se come, por lo que siempre hay un riesgo latente: ¿los seres híbridos peces-loros no expresan acaso esta constante dualidad? De acuerdo con Erikson (2000), presas/mascotas (¿peces/loros?) funcionan como dos opuestos complementarios en la lógica de las relaciones humanos-animales; de hecho, los animales cazados y los mantenidos como mascotas suelen pertenecer a la misma especie biológica, aunque se especifiquen como sujetos totalmente diferentes. Los seres duales, ¿no son en definitiva la potencialidad latente, en todo animal, de encarnar distintas afecciones?

Paralelamente al consumo de otros como comida, que lleva a la identificación entre los comensales, existe el consumo de otros en su condición de personas, que lleva a la identificación entre predador y presa. Esta forma de "consumo ontológico" (que puede ser más o menos literal) está dirigida a apropiarse de las capacidades subjetivas de aquel que es comido (Fausto, 2007). Un ejemplo es el consumo de carne cruda de animales predadores, normalmente prohibidos, con la finalidad de adquirir su valor y coraje [por ej. entre grupos Kashinawá y Yágua (Fausto, 2007)]. Otro tipo de prácticas que no implican un consumo directo también están dirigidas a adquirir un suplemento de potencia predadora, como el uso de dientes de carnívoros en collares. En el Paraná Medio y, más comúnmente, en el Delta del Paraná, es frecuente el hallazgo de pendientes elaborados a partir de colmillos de yaguareté y otros predadores (Acosta et al., 2015; Schmitz et al., 1972; Serrano, 1950; Torres, 1911). De acuerdo con los testimonios de los isleros que poblaron el Delta en el siglo XIX, recopilados por Luis María Torres (1911), los "antiguos" que tenían muchos colmillos colgados de la garganta eran las personas más valientes. Estos objetos han sido interpretados como amuletos y/o elementos utilizados para comunicar mensajes relacionados con la "esfera simbólica" de los grupos (Acosta et al., 2015). Desde un punto de vista no representacionalista, podemos pensar que la importancia de estos objetos no reside en que "simbolicen" ideas alojadas en alguna esfera separada de la existencia; no se trata de que los colmillos "representen" la fuerza y el valor del yaguareté, sino que son los vehículos cuya misma forma y sustancia hacen posible esas capacidades. Estos ornamentos, constituirían una suerte de "prótesis animales" $y$, junto con otras formas de decoración y exhibición, forman parte del proceso de particularización de los cuerpos humanos, cuya máxima expresión es, al mismo tiempo, su máxima "animalización" (Viveiros de Castro, 2018). Podemos pensar en los cuerpos humanos de los antiguos habitantes del Delta del Paraná como lienzos en blanco que fueron decorados, vestidos y modificados con elementos como plumas, dientes y pieles animales. Lopes de Souza, uno de los primeros cronistas europeos del siglo XVI, relata el encuentro con cuatro indígenas chana mbeguá quienes "... traziam na cabeça hûsbarretes [birretes] das pelles das cabeças das onças, com os dentes e com tudo" (Lopes de Souza, [1530-1532] 1839: 48, en Politis et al., 2017). Arqueológicamente, la obtención de pieles de carnívoros ha podido inferirse a 
partir de cráneos y mandíbulas de distintas especies de cánidos y félidos, que muestran huellas antrópicas de acuerdo con un patrón muy recurrente, similar al descrito para el desollado experimental (ver Politis et al., 2017) (Figura 2). El uso de pieles de animales (especialmente yaguareté) es una práctica muy difundida en tierras bajas, sobre todo entre chamanes, como medio de lograr la metamorfosis corporal necesaria para acceder a otros planos de la existencia. Aquí, nuevamente, estar en la piel del yaguareté no es una metáfora o un símbolo de algo más, sino una transformación material concreta, una forma de habitar un tipo particular de cuerpo, en la cual pueden aparecer otros tipos de cosas. En la metamorfosis, el "ropaje" no tiene la función de encubrir -a la manera de un disfraz- el verdadero cuerpo, sino que es un cuerpo. No sirve para ocultar sino para habilitar, para abrir la persona al mundo, suministrando un equipamiento distintivo dotado de habilidades y disposiciones para llevar adelante una forma de vida (Ingold, 2000; Viveiros de Castro, 2018).

En un mundo fluido de relaciones entre seres humanos, animales, espirituales, entre otros, una preocupación en las sociedades del Paraná Medio e Inferior parece haber sido la de especificar los cuerpos, ya sea a través de la familiarización entre aquellos que comen juntos o a través de transformaciones que llevan a la identificación con aquello que es "comido" o in-corporado, en sentido amplio. Cabe preguntarse si estas formas de especificar, a través de la comensalidad y la "predación ontológica", pudieron extenderse luego de la muerte. Un aspecto del registro arqueológico de la región que ha llamado recurrentemente la atención es la asociación, en espacios mortuorios, de entierros humanos con restos producidos a partir de actividades culinarias (por ej. fauna, cerámica, carbones) (Acosta y Mazza, 2016; Caggiano, 1984; Ceruti, 2003; Gaspary, 1950; Lothrop, 1932; Schmitz et al., 1972; Torres, 1911). Por ejemplo, en el sitio Los Tres Cerros 1 pudo identificarse un denso basurero en el área de inhumación (Bastourre, 2014). Distintas "actividades rituales" (festines mortuorios, disposición de ajuar funerario u ofrendas de comida) o, simplemente, la mezcla de materiales, se han propuesto como explicaciones para dar cuenta de cómo actividades "mundanas", como el descarte de los desechos de alimentación, pudieron entrecruzarse con prácticas "sagradas", el entierro de los muertos (Torres, 1911; Lothrop, 1932; Caggiano, 1984; Ceruti, 2003), aspectos que parecen difíciles de conciliar toda vez que la basura se piensa como algo inerte y sin significado. Otro aspecto interesante del registro mortuorio del Delta del Paraná es la disposición, en varios sitios, de cráneos y dientes de carnívoros junto a los restos humanos (ver Acosta y Mazza, 2016; Politis et al., 2017 y bibliografía allí citada). El hecho de que sean cráneos los elementos seleccionados para acompañar a los muertos resulta significativo si consideramos que el cuerpo puede no necesariamente entenderse como una unidad indiferenciada (Fowler, 2004); por el contrario,
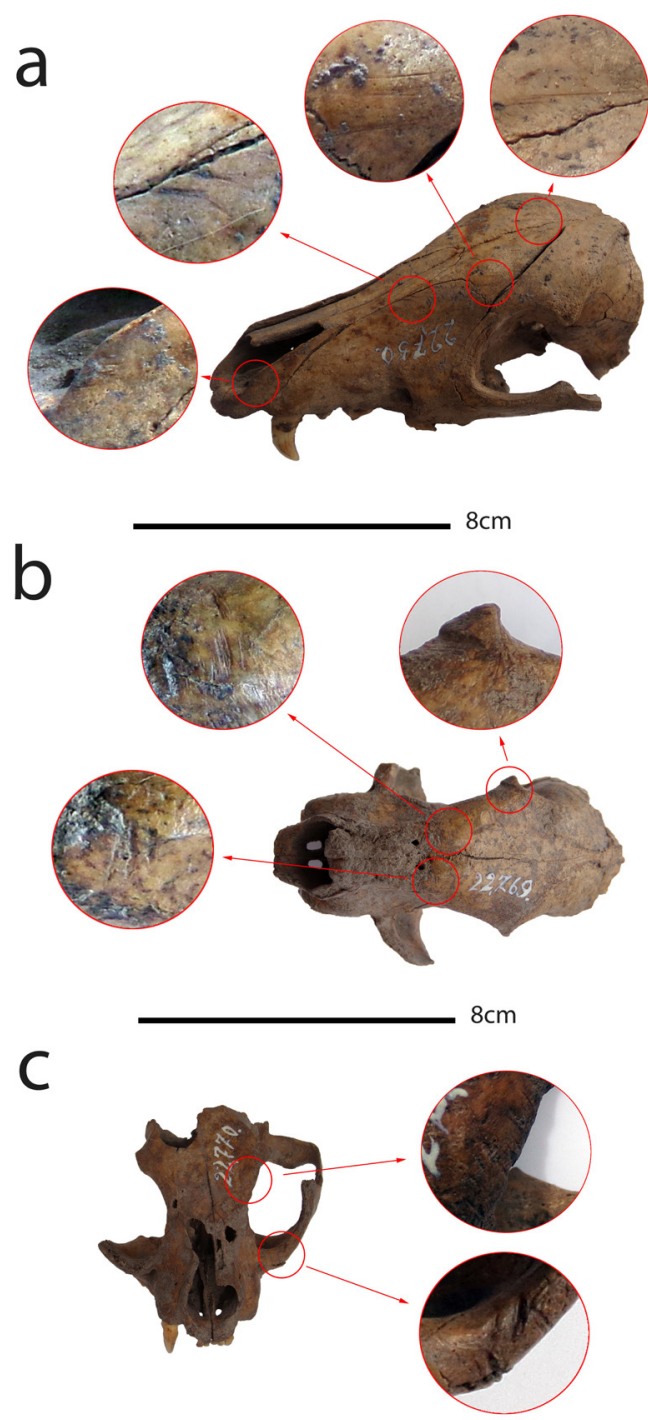

Figura 2. Cráneos de carnívoros procedentes del sitio Túmulo II del Brazo Largo (departamento Islas del Ibicuy, Entre Ríos), asignados a Cerdocyon thous (a), Herpailurus yagouaroundi (b) y Oncifelis geoffroyi (c); b y c se recuperaron en asociación a un cráneo humano. Los círculos rojos indican las zonas donde se identificaron huellas de corte, interpretadas como el resultado de actividades peleteras (ver Politis et al., 2017).

Figure 2. Carnivore skulls from Túmulo II del Brazo Largo site (Islas del Ibicuy department, Entre Ríos), assigned to Cerdocyon thous (a), Herpailurus yagouaroundi (b) and Oncifelis geoffroyi (c); $b$ and $c$ were recovered in association with a human skull. Red circules indicate the areas where cut marks were detected, which were interpreted as the result of skinning activities (see Politis et al., 2017).

algunas partes del cuerpo pueden tener más "agencia" que otras, destacándose como receptáculos privilegiados de la potencia predadora (Fausto, 2007). Como han señalado autores como Thomas (2002) y Fowler (2004), los cuerpos se encuentran en un continuo proceso performativo; las personas se constituyen, de-constituyen, mantienen y alteran a lo largo de su vida y también luego de su muerte, en un proceso relacional que involucra no solo otras personas, sino cosas, lugares, animales y 
fuerzas espirituales. Las prácticas mortuorias entre estas sociedades se caracterizan por su gran variabilidad, que incluye: entierros primarios, paquetes secundarios (que suelen combinar partes de varios individuos), huesos aislados y en aparente desorden, entierros en posición "natural" pero incompletos, entre otros (ver Ramos van Raap, 2018 y bibliografía allí citada). Así, el contexto mortuorio parece haber sido un espacio de constante manipulación y transformación. Luego de muertos, los cuerpos siguieron estando atados a flujos que, a su vez, se ensamblaron con los flujos de otros seres; continuaron formando parte de los ciclos de predación, por ejemplo, a través de la comida y mediante la asociación con fuerzas agentivas no-humanas. En un contexto de constante transformación, los cuerpos siguieron siendo especificados y producidos luego de la muerte. Las mezclas de huesos animales y humanos también han sido estudiadas por Laguens y Gastaldi (2008) para el caso de Aguada de Ambato. Aunque los contextos son muy diferentes (con sacrificios y tratamientos mortuorios similares en humanos y animales), las conclusiones son similares en cuanto al aspecto general de remarcar el potencial de este tipo de materialidades para discutir modos de identificación y formas de especificar cuerpos en contextos funerarios.

Ahora bien, ¿qué concepto de persona (humana y otras que humanas) puede haber informado este tipo de prácticas? El registro mortuorio de la región muestra la disociación entre los distintos elementos óseos del cuerpo humano y su re-asociación para formar otros tipos de "ensambles" (conjuntos dispersos de huesos, "paquetes" secundarios, etc.) que incluyen a veces también elementos no humanos (por ejemplo, cráneos de carnívoros, restos de alimentación). Durante la vida, los cuerpos humanos también se ensamblaron con partes de animales (como pieles o dientes). En este contexto, no parece aplicable el concepto moderno de persona, que remite a las ideas de individualidad e indivisibilidad: las personas son seres unitarios, con límites definidos, indivisibles, autónomos y "libres", que luego, de esta forma delimitados, entran en relaciones con otros seres similares (Fowler, 2004; Thomas, 2002). En cambio, a los fines de nuestro caso de estudio, es interesante retomar los conceptos de "dividualidad" y "partibilidad". El primero remite, según Fowler (2004), a un estado del ser en que la persona se considera en sí misma compuesta de relaciones sociales, originada por múltiples autorías, al punto tal que debe partes de sí misma a otros. Más importantemente, algunas de estas partes pueden no estar fijas en el cuerpo, sino entrar, o bien, emerger de la persona en ciertas ocasiones. Asociado a este concepto se sitúa, en espejo, la idea de partibilidad, un estado en el cual la persona dividual es reconfigurada de manera tal que una parte puede ser extraída y otorgada a otra persona. Así, las partes de una persona dividual se originan, y a la vez pertenecen, a otros. De acuerdo con Fausto (2007), la posibilidad de que convivan dos modalidades de consumo de un cuerpo, ontológica y alimentaria, es posible gracias a su partibilidad en una parte potencialmente comestible (la parte "presa") y una parte "predadora". La idea de capturar las capacidades agentivas de otros seres (por ej. coraje) a través de la adquisición de una parte de su cuerpo (por ej. los dientes) hace que podamos concebir a estas partes como una especie de suplemento que es separable y puede ser transferido de un sujeto a otro.

\section{Consideraciones finales}

Hemos explorado diferentes aspectos del involucramiento entre humanos y animales entre las sociedades prehispánicas del Paraná Medio e Inferior a la luz de enfoques teóricos que han centrado su interés en las ontologías nativas. A partir de la información arqueológica regional acerca de los modelados zoomorfos de Goya-Malabrigo se ha propuesto que los regímenes ontológicos en el pasado probablemente incluyeron una noción de "lo social" y de lo que cuenta como persona que abarcó una multiplicidad de seres. También hemos sugerido que un giro ontológico que no se limite únicamente a identificar "visiones de mundo" requiere utilizar los conceptos nativos como teorías. Esto nos ha llevado a trabajar con nociones del perspectivismo como transformación, especificación de los cuerpos y predación ontológica, que enfatizan la fluidez, inestabilidad y el carácter constitutivamente relacional de las entidades en el mundo. A partir de ello hemos propuesto nuevas formas de entender ciertas particularidades del registro material de la región, como la asociación de entierros humanos y restos de alimentación, la presencia de apéndices zoomorfos en contextos culinarios, o la obtención y uso de pieles de carnívoros y de "adornos" elaborados con sus dientes. Estos conceptos se enlazan con enfoques teóricos de la arqueología que, en los últimos años, han adquirido un importante desarrollo y que proponen ontologías plurales, relacionales, post- humanistas y con un renovado interés en la materialidad.

En la región, las relaciones humanos/animales se han conceptualizado como primordialmente económicas y "materiales" o, alternativamente, se centraron en los aspectos considerados "simbólicos", reproduciendo la ruptura ontológica naturaleza/cultura. Avanzar hacia una zooarqueología de la ontología requiere asumir que distintos aspectos de estas relaciones (alimentación, modelado de animales, uso de pieles, entre otros) constituyen todos ellos entramados de prácticas y relaciones que involucran múltiples agencias, no solo humanas, a través de los cuales los mundos son recreados. Es a partir de este proceso relacional que pueden emerger objetos y sujetos, materiales y significados, animales y humanos, sin que puedan establecerse a priori distinciones ontológicas entre ellos, ni esencias fijas.

La Plata, 13 de Julio de 2020 


\section{Agradecimientos}

A Andrés Laguens, por incentivar la apertura teórica y por la generosidad de abrir un espacio para que las y los investigadores jóvenes podamos participar de los debates teóricos contemporáneos. A Gustavo Politis, por la lectura crítica del manuscrito, y a los dos evaluadores del mismo; todos ellos contribuyeron en gran medida a mejorarlo. A Eduardo Apolinaire, por su asistencia con las figuras y por brindarme las imágenes que obtuvo durante el relevamiento de la colección del Museo de Conscripto Bernardi.

\section{Bibliografía}

Acosta, A. (2005). Zooarqueología de cazadoresrecolectores del extremo nororiental de la provincia de Buenos Aires (humedal del río Paraná inferior, Región Pampeana, Argentina) [Tesis Doctoral inédita]. Universidad Nacional de La Plata.

Acosta, A., Buc, N., Ramírez, M., Prevosti, F. y Loponte, D. (2015). Producción y uso de objetos ornamentales elaborados sobre dientes de carnívoros en contextos arqueológicos del Humedal del Paraná Inferior. Revista del Museo de Antropología, 8(2), 33-46.

Acosta, A. y Mazza, B. (2016). Restos óseos humanos y faunísticos: su relación en el espacio mortuorio en contextos de cazadores recolectores del humedal del Paraná inferior (Argentina). Pesquisas Antropologia, 72, 185-207.

Alberti, B. (2016). Archaeologies of Ontology. Annual Review of Anthropology, 45, 163-179.

Alberti, B. y Marshall, Y. (2009). Animating archaeology: local theories and conceptually open-ended methodologies. Cambridge Archaeological Journal, 19(3), 344-356.

Anderson, B. y Harrison, P. (2010). The Promise of NonRepresentational Theories. En: B. Anderson y P. Harrison (Eds.), Taking Place: Non-Representational Theories and Geography (pp. 1-34). Ashgate Publishing Group.

Århem, K. (1996). The cosmic food web: human-nature relatedness in the Northwest Amazon. En: P. Descola y G. Pálsson (Eds.), Nature and Society, Anthropological Perspectives (pp. 185-204). Routledge.

Bastourre, M.L. (2013). Integrando la información arqueofaunística a la discusión de la entidad arqueológica Goya-Malabrigo. En: Resúmenes del V Encuentro de Discusión de Arqueología del Nordeste Argentino, (1416). Goya, Corrientes.

Bastourre, M.L. (2014). Estudios arqueofaunísticos en el Delta Superior del Paraná: el sitio Los Tres Cerros 1 (provincia de Entre Ríos, Argentina). Revista Chilena de Antropología, 30(2), 109-115.

Bastourre, M.L. y Azpelicueta, M. de las M. (2020). Del registro ictioarqueológico a las prácticas alimentarias: el caso de Los Tres Cerros 1 (Delta Superior del Paraná, Entre Ríos). Relaciones de la Sociedad Argentina de Antropología, 45(1), 13-57.

Bird-David, N. (1999). "Animism" revisited: Personhood, Environment, and Relational Epistemology. Current Anthropology, 40 (Supplement), S67-S91.

Bonomo, M. (2012). Historia Prehispánica de Entre Ríos. Fundación Félix de Azara.

Bonomo, M., Castro, J.C. y Silva, C.B. (2014). Tecnología y subsistencia en el sitio arqueológico Cerro Tapera Vázquez (Parque Nacional Pre-Delta, República Argentina). Cadernos do Lepaarq, 11(22), 53-81.

Bonomo, M., Politis, G., Bastourre, M.L. y Moreira, G. (2020). Humanized Nature: Symbolic Representation of Fauna in Pottery from The Paraná River of South America. En: M. Bonomo y S. Archila (Eds.), South American Contributions to World Archaeology (en prensa). One World Archaeology Series, Springer-Nature.

Caggiano, M.A. (1984). Prehistoria del N.E. argentino. Sus vinculaciones con la República Oriental del Uruguay y sur de Brasil. Pesquisas, 38, 5-109.

Ceruti, C. (2003). Entidades culturales presentes en la cuenca del Paraná Medio (margen entrerriana). Mundo de Antes, 3, 111-135.

Conneller, C. (2011). An Archaeology of Materials. Substantial Transformations in Early Prehistoric Europe. Routledge.

Cornero, S. (2018). En las puertas del mito: loros y peces en el arte cerámico de la costa del río Paraná. En: G. Politis y M. Bonomo (Eds.), Goya-Malabrigo: arqueología de una sociedad indígena del noreste argentino (pp. 89106). Editorial UNICEN.

Cornero, S. (2019). Cóndores del Paraná. Análisis de cerámicas catártidas en la costa del Paraná. Sociedades de paisajes áridos y semiáridos, 12(1), 138-159.

Cornero, S. (2020). Acerca de la figura humana en la trasformación simbólica: diseños en la cerámica arqueológica del Paraná Medio. ANTI, Revista del Centro de Investigaciones Precolombinas, 17(2), 12-35.

Descola, P. (1988). La selva culta: simbolismo y praxis en la ecología de los Achuar. Abya Yala- IFEA. 
Descola, P. (2011). Más allá de la naturaleza y de la cultura. En L. Montenegro Martínez (Ed.), Cultura y Naturaleza. Aproximaciones a propósito del bicentenario de la independencia de Colombia (pp. 75-96). Jardín Botánico de Bogotá, José Celestino Mutis.

Descola, P. (2014). Modes of being and forms of predication. Hau: Journal of Ethnographic Theory, 4(1), 271-280.

Di Prado, V. (2015). Estudio comparativo de las prácticas de elaboración y uso de la alfarería prehispánica del centro-este de Argentina desde una perspectiva macrorregional. [Tesis Doctoral inédita]. Universidad Nacional de La Plata.

Erikson, P. (2000). The social significance of pet-keeping among Amazonian Indians. En A. Podberscek, E. Paul y J. Serpell (Eds.), Companion animals and us: Exploring the relationships between people and pets (pp. 7-26). Cambridge University Press.

Fausto, C. (2001). Inimigos Fiéis: História, Guerra e Xamanismo na Amazônia. Editora da Universidade de São Paulo.

Fausto, C. (2007). Feasting on People. Eating Animals and Humans in Amazonia. Current Anthropology, 48(4), 497-530.

Fowler, C. (2004). The Archaeology of Personhood. Routledge.

Gaspary, F. (1950). Investigaciones Arqueológicas y Antropológicas en un Cerrito de la Isla Los Marinos (Pcia. de Entre Ríos). Publicación del Instituto de Arqueología, Lingüística y Folklore, 23, 3-66.

Haber, A.F. (2004). Arqueología de la naturaleza, naturaleza de la arqueología. En: A.F. Haber (Ed.), Hacia una arqueología de las arqueologías sudamericanas (pp. 15-32). Universidad de los Andes, Facultad de Ciencias Sociales, Centro de Estudios Socioculturales e Internacionales, Bogotá.

Harris, O.T. (2018). More than representation: multi-scalar assemblages and the Deleuzian challenge to archaeology. History of the Human Sciences, 31(3), 83-104.

Harvey, G. (2014). The handbook of contemporary animism. Routledge.

Henare, A., Holbraad, M. y Wastell, S. (2007). Thinking Through Things. Theorizing Artefacts Ethnographically. Routledge.

Ingold, T. (2000). The perception of the environment: Essays on livelihood, dwelling and skill. Routledge.
Ingold, T. (2012). Toward an Ecology of Materials. Annual Review of Anthropology, 41, 427-442.

Jones, A.M. y Alberti, B. (2013). Archaeology after interpretation. En: B. Alberti, A.M. Jones y J. Pollard (Eds.), Archaeology after interpretation. Returning materials to archaeological theory (pp. 15-42). Walnut Creek.

Laguens, A. y Gastaldi, M. (2008). Registro material, fisicalidad, interioridad, continuidad y discontinuidad: posiciones y oposiciones frente a la naturaleza y las cosas. En: D. Jackson, D. Salazar y A. Troncoso (Eds.), Puentes hacia el pasado, reflexiones teóricas en arqueología (pp. 169-189). Universidad de Chile.

Latour, B. (2005). Reensamblar lo social. Una introducción a la teoría del actor-red. Manantial.

Lothrop, S. (1932). Los indios del Delta del Paraná. Annals of the New York Academy of the Sciences, 33, 77-232.

Olsen, B. y Witmore, C. (2015). Archaeology, symmetry and the ontology of things. A response to critics. Archaeological Dialogues, 22(2), 187-197.

Ottalagano, F. (2007). Algunas referencias en torno al simbolismo de las aves en los registros etnohistóricos y etnográficos de Guaycurúes y Mataco-Mataguayos. Arqueología Suramericana, 3(2), 213-228.

Ottalagano, F. (2008). Hacia la identificación taxonómica de las representaciones de psitácidos en la cerámica de la cuenca del Río Paraná. Comechingonia, 11(1), 79-98.

Ottalagano, F. (2010). Simbolismo e identidad en las tierras bajas del Paraná: un abordaje contextual del arte mobiliar cerámico. Relaciones de la Sociedad Argentina de Antropología, 35, 195-218.

Ottalagano, F. y Colobig, M.M. (2010). Concepciones de aves y felinos en los relatos de un informante chaná: entrevista a Blas Jaime. Revista de la Escuela de Antropología de la Universidad Nacional de Rosario, 16, 91-102.

Pazzarelli, F.G. (2013). Otros-maíces: trayectorias y transformaciones culinarias del maíz en Ambato (Catamarca, Noroeste Argentino). Revista Española de Antropología Americana, 43(2), 329-351.

Politis, G., Bastourre, M.L., Di Prado, V., Bonomo, M., Moreira, G. y Matarrese, A. (2017). El Túmulo II del Brazo Largo. Aportes para la arqueología del Delta Inferior del río Paraná. Revista del Museo de Antropología, 10(2), 71-88.

Politis, G. y Bonomo, M. (2012). La entidad arqueológica Goya-Malabrigo (ríos Paraná y Uruguay) y su filiación 
Arawak. Revista de Arqueología, 25(1), 10-46.

Politis, G. y Bonomo, M. (2015). Una revisión del Túmulo de Campana. Relaciones de la Sociedad Argentina de Antropología, 40(1), 149-181.

Politis, G. y Bonomo, M. (2018). Estado actual y perspectivas de Goya-Malabrigo, una sociedad indígena del Noreste argentino. En: G. Politis y M. Bonomo (Eds.), Goya-Malabrigo: arqueología de una sociedad indígena del noreste argentino (pp. 9-44). Editorial UNICEN.

Politis, G. y Saunders, N. (2002). Archaeological correlates of ideological activity: food taboos and spirit-animals in an Amazonian hunter-gatherer society. En: P. Miracle y N. Milner (Eds.), Consuming Passions and Patterns of Consumption (pp. 113-130). McDonald Institute for Archaeological Research, University of Cambridge.

Ramos van Raap, M.A. (2018). Caracterización del registro mortuorio de la entidad arqueológica Goya-Malabrigo. En: G. Politis y M. Bonomo (Eds.), Goya-Malabrigo: arqueología de una sociedad indígena del noreste argentino (pp. 175-199). Editorial UNICEN.

Schmitz, P., Ceruti, C., González, A.R. y Rizzo, A. (1972). Investigaciones arqueológicas en la zona de Goya (Corrientes), Argentina. Dédalo, 8(15), 11-121.

Serrano, A. (1950). Los primitivos habitantes de Entre Ríos. Biblioteca Entrerriana "General Perón", Ministerio de Educación, Provincia de Entre Ríos.

Thomas, J. (2002). Archaeology's Humanism and the
Materiality of the Body. En: Y. Hamilakis, M. Pluciennik y S. Tarlow (Eds.), Thinking through the body. Archaeologies of corporeality (pp. 29-45). Kluwer Academic/Plenum Publishers.

Torres, L.M. (1911). Los primitivos habitantes del Delta del Paraná. Biblioteca Centenaria, Universidad Nacional de La Plata.

Vilaça, A. (2002). Making kin out of others. Journal of the Royal Anthropological Institute, 8, 347-365.

Viveiros de Castro, E. (2002). O Nativo relativo. Maná, 8(1), 113-148.

Viveiros de Castro, E. (2003). (anthropology) AND (science). Manchester Papers in Social Anthropology, 7.

Viveiros de Castro, E. (2004a). Exchanging Perspectives. The Transformation of Objects into Subjects in Amerindian Ontologies. Common Knowledge, 10 (3), 463-484.

Viveiros de Castro, E. (2004b). Perspectival anthropology and the method of controlled equivocation. Tipiti, 2(1), $3-22$.

Viveiros de Castro, E. (2010). Metafísicas Caníbales: Líneas de Antropología Postestructural. Katz Editores.

Viveiros de Castro, E. (2018). La inconstancia del alma salvaje. Universidad Nacional de General Sarmiento.

Walker, H. (2010). Soulful Voices: Birds, Language and Prophecy in Amazonia. Tipití, 8(1), 1-21. 